\title{
Analysis of the current status and associated factors of tuberculosis knowledge, attitudes, and practices among elderly people in Shenzhen: a cross- sectional study
}

Yunxia Wang ${ }^{1 \dagger}$, Yong Gan ${ }^{2 \dagger}$, Juanjuan Zhang ${ }^{1}$, Jinzhou Mei ${ }^{1}$, Jing Feng ${ }^{2}$, Zuxun Lu ${ }^{2}$ Xin Shen ${ }^{2}$, Meigui Zhao , Yanfang Guo ${ }^{1}$ and Qing Yuan ${ }^{* *}$

\begin{abstract}
Background: The incidence and risk of tuberculosis (TB) among the elderly population have increased with the ageing population in China. This study aimed to assess the current status and associated factors of TB knowledge, attitudes, and practices among elderly people in Shenzhen City, China, which may provide references for the development of TB prevention and treatment policies targeting elderly people.

Methods: A multistage random sampling method was used to collect data with a self-designed questionnaire from 1078 elderly people (response rate, 90.66\%) living in Bao'an District of Shenzhen between September and October 2019. Univariate and multiple linear regression analyses were used to analyse factors associated with TB knowledge, attitudes, and practices among elderly people.

Results: Among the respondents, 3.13\% had previously been treated for TB, and 3.09\% of respondents had family members or friends with a previous TB history. The percentages of elderly people who were aware of TB and had positive attitudes and practices regarding TB were $69.23 \%, 48.87 \%$, and $42.62 \%$, respectively. Multiple linear stepwise regression analysis showed that elderly people with a junior high school education or higher, a family annual income per capita of less than 100,000 RMB, a better self-perceived health status, and family members or friends with a previous TB history had higher TB knowledge scores $(P<0.05)$. Elderly people with medical insurance, a junior high school or higher education, a family annual income per capita of less than 100,000 RMB, and family members and friends with a previous TB history had higher TB attitude scores $(P<0.05)$. In addition, elderly people who were older, had medical insurance, had a junior high school education or higher, and had a family annual income per capita less than 100,000 RMB had higher TB practice scores $(P<0.05)$.
\end{abstract}

\footnotetext{
*Correspondence: yuanq_12@163.com

${ }^{\dagger}$ Yunxia Wang and Yong Gan contributed equally to this work.

'Shenzhen Bao'an Center for Chronic Disease Control, NO. 332 Yu'an 2nd Road, Shenzhen 518101, China

Full list of author information is available at the end of the article
}

(c) The Author(s). 2021, corrected publication 2021. Open Access This article is licensed under a Creative Commons Attribution 4.0 International License, which permits use, sharing, adaptation, distribution and reproduction in any medium or format, as long as you give appropriate credit to the original author(s) and the source, provide a link to the Creative Commons licence, and indicate if changes were made. The images or other third party material in this article are included in the article's Creative Commons licence, unless indicated otherwise in a credit line to the material. If material is not included in the article's Creative Commons licence and your intended use is not permitted by statutory regulation or exceeds the permitted use, you will need to obtain permission directly from the copyright holder. To view a copy of this licence, visit http://creativecommons.org/ licenses/by/4.0/. The Creative Commons Public Domain Dedication waiver (http://creativecommons.org/publicdomain/zero/1. 0/) applies to the data made available in this article, unless otherwise stated in a credit line to the data. 
Conclusions: Elderly people were aware of TB, but their positive attitudes and practices were at a low level. Corresponding prevention and treatment policies should be developed according to these influencing factors to reduce the incidence of TB among elderly people and improve their quality of life.

Keywords: Tuberculosis, Knowledge, Attitude, Practice, Elderly people

\section{Background}

The Global Tuberculosis (TB) Report issued by the World Health Organization (WHO) showed approximately 10 million new TB patients worldwide in 2019, $86 \%$ of whom were concentrated in 30 countries with a high TB burden [1]. China has a high TB burden, with approximately 833,000 new TB patients every year, ranking second in the world behind India [1]. The TB epidemic is growing markedly, with a progressive increase in the notification rate with age, and a peak among those aged 65 years or older [1]. As the population has aged rapidly in China in recent years, the WHO estimates that the number of elderly people in China will reach 402 million by 2040 , accounting for $28 \%$ of the total population [2]. A cohort study in 2020 showed that the incidence and risk of $\mathrm{TB}$ among the elderly population increased with the ageing of the population in China, and the detection rate of TB among the elderly population was 481.8/100,000 [3]. The high incidence of TB among elderly people has introduced considerable challenges to the lives of Chinese people and China's economy. Understanding the knowledge, attitudes, and practices (KAP) and associated factors related to $\mathrm{TB}$ among elderly people is very important to the targeted development of TB prevention and treatment tasks in China.

Previous studies have investigated TB KAP among medical interns, nurses, teacher trainees, healthcare workers, and community residents [4-8]. Berg-Johnsen et al. conducted a study on 270 medical interns and found that the surveyed interns had an adequate level of TB-related knowledge and acceptable attitudes [4]. Akande reported that small proportions of the respondents had a good score for knowledge (10.5\%) and practices (6\%) [5]. Dorji et al. surveyed 420 trainees and revealed that $58.6 \%$ had low knowledge of TB [6]. Alotaibi et al. conducted a study of 540 healthcare workers and found that the participants had average knowledge, above-average attitude, and good practice regarding TB [7]. Wang et al. conducted a national survey of 33,357 residents and showed an overall $\mathrm{TB}$ awareness rate of $74.45 \%$ [8]. However, no studies have investigated TB KAP and associated factors among elderly people in the community. Therefore, this study aimed to address this important research gap. The findings from this study may contribute to developing TB prevention and treatment policies for elderly people.

\section{Methods}

\section{Study population and sampling}

Multistage random sampling was performed between September and October 2019. First, two of eight community health service centres with chest X-ray film screening capabilities in Bao'an District of Shenzhen were randomly selected. Next, six hundred people aged 65 years or older who received health examinations were randomly selected from each community health service centre. Elderly people in the study communities who met the following criteria were included in the survey: (1) aged 65 years and older; (2) residence in the area for at least half a year; (3) no communication disorders or mental illnesses; and (4) willingness to complete the survey. Individuals were excluded if they did not meet one of the above requirements.

The sample size was calculated using the formula, $\mathrm{n}=$ $\left[\mathrm{Z}^{2} \mathrm{p}(1-\mathrm{p})\right] / \mathrm{d}^{2}$ (where $\mathrm{n}=$ sample size, $\mathrm{Z}=$ confidence level for a normal distribution, $\mathrm{p}=$ estimated proportion, and $\mathrm{d}=$ absolute error) [9]. Taking a confidence interval $(C I)$ of $95 \%$ with a probability of $51.4 \%$ [10] and a margin of error at $5 \%$, the sample size was rounded off to 400. To compensate for nonresponses, the sample size was increased by $10 \%$ to 440 . Thus, the sample size was sufficient in our study.

This study was approved by the ethics committee of Tongji Medical College institutional review board, Huazhong University of Science and Technology, Wuhan, China. All methods were carried out in accordance with relevant guidelines and regulations.

\section{Questionnaire design and measurement}

A cross-sectional study was performed to collect data from the elderly population using a structured questionnaire. The survey questionnaire was designed according to core information on TB prevention and treatment in China (2016 edition) [11], available questionnaires in previous literatures $[10,12,13]$, and the actual conditions of elderly people in Shenzhen city. The questionnaire included two parts; the first part collected information on gender, age, residence, education level, marital status, occupation, medical insurance, family annual income per capita, self-perceived health status, body mass index (BMI), tobacco use, alcohol consumption, previous TB history, and family members or friends with a previous TB history. The second part examined the subjects' KAP regarding the prevention and 
treatment of TB. TB KAP was examined with 5, 5, and 6 items respectively, including TB epidemiology, transmission, treatment, and infection prevention and control. Incorrect/inappropriate or uncertain (did not know) responses were given a score of 0 , while 1 point was assigned for selecting the correct/appropriate answer; correct/appropriate responses were based on current literature and best practice. Respondents who answered $60 \%$ of the KAP questions correctly were considered aware of $\mathrm{TB}$ and to have positive attitudes or practices regarding $\mathrm{TB}$.

\section{Data collection and quality control}

We designed the questionnaire based on a literature review, group discussions, and expert consultation. To improve the quality of the questionnaire, a pretest was conducted at Shenzhen's community health service centres. Then, trained investigators administered the questionnaire to elderly people. Questionnaires were recovered on-site and the completeness of the questionnaires was verified. The data were entered into the database in a double-blind manner by two different researchers using EpiData 3.1 to guarantee accuracy.

\section{Statistical analysis}

All statistical analyses were performed using Statistical Package for Social Sciences (SPSS, Inc., Chicago, IL, Version 13.0). Descriptive analyses used the mean, standard deviation (SD), median, and interquartile range (IQR) for continuous variables and percentages for categorical data. Univariate linear regression analysis was performed to identify associations between different predictive variables and TB KAP among elderly people. Multiple linear stepwise regression was used to estimate factors associated with TB KAP among elderly people (levels for selection and elimination: $P=0.05$ and $P=0.10$, respectively). TB KAP scores were used as dependent variables, and the predictive variables included age, BMI, gender, residence, education level, marital status, occupation, medical insurance, annual family income per capita, self-perceived health status, tobacco use, alcohol consumption, previous TB history, and family members or friends with a previous TB history.

\section{Results}

Initially, a total of 1200 elderly people were randomly recruited for the survey. Eleven elderly people refused to participate and 1189 completed questionnaires were received. Then, we excluded 17 interviewees aged $<65$

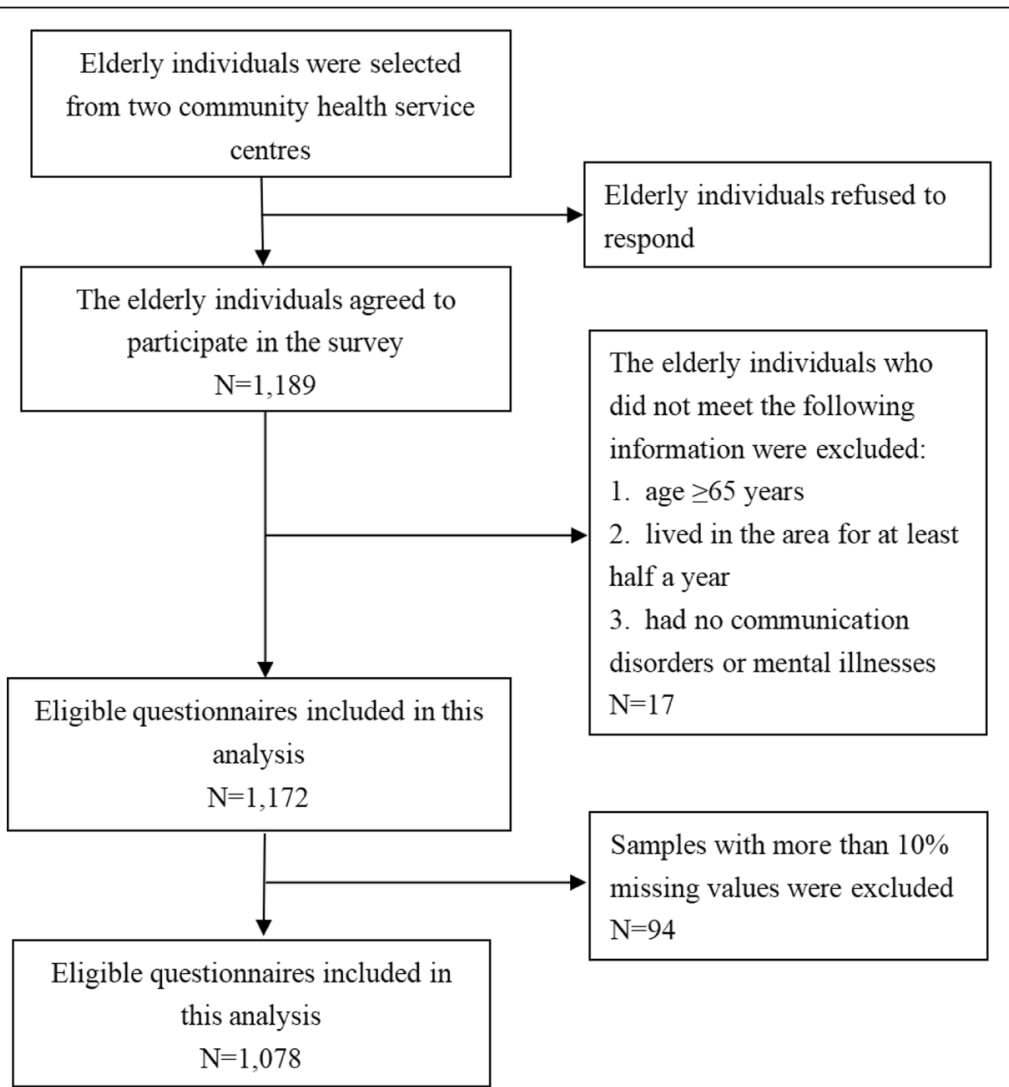

Fig. 1 The flow chart for sampling in this study 
years, residing in the area for less than half a year, and with communication disorders and mental illnesses. During the statistical analysis, 94 samples with more than $10 \%$ missing values for the items of knowledge, attitudes, and practices were excluded. Finally, a total of 1078 samples were included in this study, yielding a response rate of $90.66 \%$ (see Fig. 1).

Table 1 shows the basic characteristics of elderly people. Among 1078 respondents, 488 (45.40\%) were females, and 587 (54.60\%) were males. Most elderly people $(77.68 \%)$ were nonlocal residents. A total of 582 (54.65\%) respondents had a primary school education or below. Most (89.37\%) elderly people were married, $80.95 \%$ were farmers or worked in other occupations and $72.89 \%$ had medical insurance. Elderly people with a family annual income per capita lower than 100,000 RMB accounted for $71.44 \%$ of the total sample. A total of $494(47.45 \%)$ and 481 (46.21\%) respondents reported a good or fair self-perceived health status respectively. A total of 118 (10.97\%) and 100 (9.28\%) elderly individuals were current cigarette smokers or alcohol drinkers, respectively. Among the population, 33 (3.13\%) had previously been treated for TB, and 33 (3.09\%) had family members or friends with a previous $\mathrm{TB}$ history. In addition, the average age of the elderly individuals was $71.42(\mathrm{SD}=5.22)$ years, and the average BMI was 23.67 $(\mathrm{SD}=3.33) \mathrm{kg} / \mathrm{m}^{2}$.

The mean TB KAP scores were $3(\mathrm{IQR}=2$; range 0 to 5), $2(\mathrm{IQR}=1$; range 0 to 5$)$, and $3(\mathrm{IQR}=2$; range 0 to $6)$. The percentages of elderly people who were aware of $\mathrm{TB}$ and had positive attitudes and practices were $69.23 \%$, $48.87 \%$, and $42.62 \%$ respectively.

The distribution of participants' responses regarding TB KAP is shown in Table 2. In the knowledge section,

Table 1 Characteristics of the study populations

\begin{tabular}{|c|c|c|c|}
\hline Variables & & $\mathrm{n} /$ mean & $\% / S D$ \\
\hline Total & & 1078 & 100.00 \\
\hline Age (years) & & 71.42 & 5.22 \\
\hline BMI $\left(\mathrm{kg} / \mathrm{m}^{2}\right)$ & & 23.67 & 3.33 \\
\hline \multirow[t]{2}{*}{ Gender } & Male & 488 & 45.40 \\
\hline & Female & 587 & 54.60 \\
\hline \multirow[t]{2}{*}{ Residence } & Local residents & 237 & 21.99 \\
\hline & Others & 825 & 77.68 \\
\hline \multirow[t]{2}{*}{ Education level } & Primary school or lower & 582 & 54.65 \\
\hline & Junior high school or higher & 483 & 45.35 \\
\hline \multirow[t]{2}{*}{ Marital status } & Married & 933 & 89.37 \\
\hline & Unmarried/widowed/divorced & 111 & 10.68 \\
\hline \multirow[t]{2}{*}{ Occupation } & Workers or administrators & 204 & 19.05 \\
\hline & Farmers or others & 867 & 80.95 \\
\hline \multirow[t]{2}{*}{ Medical insurance } & Yes & 769 & 72.89 \\
\hline & No & 286 & 27.11 \\
\hline \multirow[t]{2}{*}{ Family annual income per capita (RMB) } & Less than 100,000 & 743 & 71.44 \\
\hline & More than 100,000 & 297 & 28.56 \\
\hline \multirow[t]{3}{*}{ Self-perceived health status } & Good & 494 & 47.45 \\
\hline & Fair & 481 & 46.21 \\
\hline & Bad & 66 & 6.34 \\
\hline \multirow[t]{2}{*}{ Cigarette smoker } & Current smoker & 118 & 10.97 \\
\hline & Ex/non-smoker & 958 & 89.03 \\
\hline \multirow[t]{2}{*}{ Alcohol drinker } & Current drinker & 100 & 9.28 \\
\hline & Ex/non-drinker & 978 & 90.72 \\
\hline \multirow[t]{2}{*}{ Previously treated for TB } & Yes & 33 & 3.13 \\
\hline & No & 1020 & 96.87 \\
\hline \multirow[t]{2}{*}{ Family members or friends with a previous TB history } & Yes & 33 & 3.09 \\
\hline & No & 1036 & 96.91 \\
\hline
\end{tabular}

Abbreviations: $\mathrm{SD}=$ standard deviation, $\mathrm{BMI}=$ body mass index, $\mathrm{TB}=$ tuberculosis 
Table 2 The distribution of participants' responses regarding TB KAP $(n=1078)$

\section{Items}

Knowledge

Infectivity of TB

Yes

No

Do not know

Route of TB transmission

Touching items

Sharing utensils

Coughing or sneezing

All of the above

Do not know

TB symptoms n

$\%$

$\begin{array}{ll}779 & 72.60 \\ 83 & 7.74 \\ 211 & 19.66\end{array}$

85

7.94

117

10.93

332

31.03

319

29.81

217

20.28

Headache or dizziness

2.35

Coughing for longer than 2 weeks or coughing up

Abdominal pain or diarrhoea

0.47

Do not know

23.24

Prevention and control of TB

Covering mouth and nose when coughing or sneezing

17.18

Wearing a mask

4.76

Good nutrition

Washing hands after touching items in public

All of the above

184

1.96

21

4.48

48

71.62

Curability of TB

Yes
No
Do not know

477

277

299

45.30

26.31

28.40

\section{Attitudes}

Do you think that TB is a terrible disease?

Yes

Would you like to learn about TB?

Yes

Do not sure

Would you like to participate in TB education activities?

$\begin{array}{ll}\text { Yes } & 92 \\ \text { No } & 26\end{array}$

Do not sure

Are you willing to complete treatment if you have TB?

$\begin{array}{ll}\text { Yes } & 261 \\ \text { No } & 410\end{array}$


Table 2 The distribution of participants' responses regarding TB KAP $(n=1078)$ (Continued)

\begin{tabular}{|c|c|c|c|}
\hline Items & Responses & $\mathbf{n}$ & $\%$ \\
\hline \multicolumn{4}{|c|}{ Would you be willing to be screened for TB if you had suggestive symptoms? } \\
\hline & Yes & 387 & 36.44 \\
\hline & No & 494 & 46.52 \\
\hline & Do not sure & 181 & 17.04 \\
\hline \multicolumn{4}{|c|}{ Practices } \\
\hline \multicolumn{4}{|c|}{ Have you ever taken the initiative to learn about TB? } \\
\hline & Yes & 354 & 33.08 \\
\hline & No & 716 & 66.92 \\
\hline \multicolumn{4}{|c|}{ Would you urge your friends with suspicious TB symptoms visit the doctor? } \\
\hline & Yes & 649 & 60.54 \\
\hline & No & 335 & 31.25 \\
\hline & Do not sure & 88 & 8.21 \\
\hline \multicolumn{4}{|c|}{ Would you visit a health facility if you had a cough for more than 2 weeks? } \\
\hline & Yes & 903 & 84.08 \\
\hline & No & 131 & 12.20 \\
\hline & Do not sure & 40 & 3.72 \\
\hline \multicolumn{4}{|c|}{ Would you visit a health facility if you suspected that you had TB? } \\
\hline & Yes & 916 & 85.69 \\
\hline & No & 132 & 12.35 \\
\hline & Do not sure & 21 & 1.96 \\
\hline \multicolumn{4}{|c|}{ Would you stop spitting in public? } \\
\hline & Yes & 313 & 33.02 \\
\hline & No & 580 & 61.18 \\
\hline & Do not sure & 55 & 5.80 \\
\hline \multicolumn{4}{|c|}{ Would you cover your mouth and nose when coughing or sneezing? } \\
\hline & Yes & 265 & 25.09 \\
\hline & No & 791 & 74.91 \\
\hline
\end{tabular}

Abbreviations: $\mathrm{TB}=$ tuberculosis, $\mathrm{KAP}=$ knowledge, attitudes, and practices

more than $70 \%$ of the elderly individuals $(72.60 \%$, $73.94 \%$, and $71.62 \%$ ) were aware of TB infectivity, symptoms, and preventive measures, respectively. The awareness rate for TB curability was $45.30 \%$. However, less than one-third of survey respondents (31.03\%) knew the route of TB transmission. In terms of attitudes, most elderly people $(86.03 \%$ and $86.89 \%)$ wanted to learn about TB or participate in TB education activities, respectively. More than one-third of respondents (36.44\%) were willing to be screened for TB if they had suggestive symptoms. Only 225 (21.15\%) and 261 (24.90\%) participants did not think that TB is a terrible disease or were willing to complete treatment if diagnosed with TB. Regarding practices, most elderly individuals $(84.08 \%$ and $85.69 \%$ ) would visit health facilities if they had a cough for more than 2 weeks or if they suspected that they had TB, respectively. More than half of elderly people (60.54\%) would urge their friends with suspicious symptoms to visit the doctor. Approximately one-third of participants (33.08\% and 33.02\%) had ever taken the initiative to learn about TB or would stop spitting in public, respectively. Only 265 (25.09\%) respondents covered their mouths and noses when coughing or sneezing.

Table 3 presents the results of the univariate linear regression analysis of TB KAP among the elderly population. Significant differences in TB knowledge among elderly people were observed across education levels, medical insurance statuses, family annual incomes per capita, self-perceived health statuses, previous TB histories, and family members or friends with a previous TB history $(P<0.05)$. Significant differences in TB attitudes among elderly people were found across BMIs, education levels, occupations, medical insurance statuses, family annual incomes per capita, previous TB histories, and family members or friends with a previous TB history $(P<0.05)$. Significant 
Table 3 Univariate linear regression analysis of KAP regarding TB among the elderly population

\begin{tabular}{|c|c|c|c|c|c|c|c|c|c|}
\hline \multirow[t]{2}{*}{ Variables } & \multicolumn{3}{|c|}{ Knowledge } & \multicolumn{3}{|c|}{ Attitudes } & \multicolumn{3}{|c|}{ Practices } \\
\hline & $B$ & $95 \% \mathrm{Cl}$ & $P$ & $B$ & $95 \% \mathrm{Cl}$ & $P$ & $B$ & $95 \% \mathrm{Cl}$ & $P$ \\
\hline Age (years) & 0.002 & -0.012 to 0.017 & 0.771 & 0.007 & -0.006 to 0.021 & 0.305 & 0.022 & 0.004 to 0.040 & 0.020 \\
\hline BMl $\left(\mathrm{kg} / \mathrm{m}^{2}\right)$ & -0.017 & -0.040 to 0.005 & 0.137 & -0.022 & -0.043 to -0.001 & 0.036 & -0.019 & -0.047 to 0.008 & 0.167 \\
\hline Gender (ref. male) & -0.090 & -0.243 to 0.063 & 0.247 & -0.054 & -0.194 to 0.087 & 0.453 & 0.036 & -0.147 to 0.220 & 0.698 \\
\hline Residence (ref. local residents) & -0.108 & -0.293 to 0.076 & 0.248 & -0.003 & -0.174 to 0.169 & 0.975 & -0.334 & -0.558 to -0.110 & 0.003 \\
\hline $\begin{array}{l}\text { Education level (ref. primary } \\
\text { school or lower) }\end{array}$ & 0.286 & 0.133 to 0.438 & $<0.001$ & 0.275 & 0.135 to 0.415 & $<0.001$ & 0.318 & 0.134 to 0.503 & 0.001 \\
\hline Marital status (ref. married) & -0.208 & -0.279 to 0.222 & 0.825 & 0.168 & -0.060 to 0.396 & 0.149 & 0.217 & -0.076 to 0.509 & 0.147 \\
\hline $\begin{array}{l}\text { Occupation (ref. workers or } \\
\text { administrators) }\end{array}$ & -0.119 & -0.313 to 0.075 & 0.230 & -0.331 & -0.488 to -0.134 & 0.001 & -0.381 & -0.617 to -0.144 & 0.002 \\
\hline Medical insurance (ref. yes) & -0.260 & -0.432 to -0.088 & 0.003 & -0.467 & -0.624 to -0.310 & $<0.001$ & -0.563 & -0.763 to -0.363 & $<0.001$ \\
\hline $\begin{array}{l}\text { Family annual income per capita } \\
\text { (RMB) (ref. less than 100,000) }\end{array}$ & -0.229 & -0.470 to -0.128 & 0.001 & -0.300 & -0.457 to -0.143 & $<0.001$ & -0.458 & -0.664 to -0.251 & $<0.001$ \\
\hline Self-perceived health status & -0.211 & -0.338 to -0.084 & 0.001 & -0.063 & -0.180 to 0.055 & 0.298 & -0.192 & -.342 to -0.041 & 0.013 \\
\hline Cigarette smoker (ref. current smoker) & -0.113 & -0.357 to 0.130 & 0.360 & -0.152 & -0.377 to 0.073 & 0.186 & -0.031 & -0.327 to 0.265 & 0.837 \\
\hline Alcohol drinker (ref. current drinker) & 0.054 & -0.208 to 0.315 & 0.686 & 0.024 & -0.217 to 0.264 & 0.846 & 0.007 & -0.320 to 0.334 & 0.966 \\
\hline Previously treated for TB (ref. no) & 0.668 & 0.235 to 1.101 & 0.003 & 0.406 & 0.002 to 0.810 & 0.049 & 0.755 & 0.232 to 1.278 & 0.005 \\
\hline Family members or friends with a & 0.709 & 0.272 to 1.147 & 0.002 & 0.829 & 0.432 to 1.225 & $<0.001$ & 0.448 & -0.065 to 0.962 & 0.087 \\
\hline
\end{tabular}

previous TB history (ref. no)

Abbreviations: $\mathrm{KAP}=$ knowledge, attitudes, and practices, $\mathrm{TB}=$ tuberculosis, $\mathrm{BMI}=$ body mass index

* The self-perceived health status variable was rated as follows: good $=1$, fair $=2$, bad $=3$

differences in TB practices among elderly people were identified across ages, residences, education levels, occupations, medical insurance statuses, family annual incomes per capita, self-perceived health statuses, previous $\mathrm{TB}$ histories, and family members or friends with a previous TB history $(P<0.05)$.

Multiple stepwise regression analyses showed that education level (junior high school or higher: $\beta=0.278$, 95\% CI 0.108 to $0.447 ; P=0.001$ ), annual family income per capita (more than 100,000: $\beta=-0.377,95 \% \mathrm{CI}-$ 0.563 to $-0.191 ; P<0.001$ ), self-perceived health status $(\beta=-0,245,95 \% C I-0.387$ to $-0.103 ; P=0.001)$, and having family members or friends with a previous TB history (yes: $\beta=0.624,95 \%$ CI 0.157 to $1.091 ; P=0.009$ ) were associated with TB knowledge among elderly people (Table 4). Medical insurance (no: $\beta=-0.409$, 95\% $C I-0.584$ to $-0.235 ; P<0.001$ ), education level (junior high school or higher: $\beta=0.208,95 \%$ CI 0.052 to 0.364; $P=0.009$ ), family annual income per capita (more than 100,000: $\beta=-0.224,95 \% C I-0.394$ to -0.053 ; $P=0.010$ ), and having family members or friends with a previous TB history (yes: $\beta=0.753,95 \%$ CI 0.332 to 1.174; $P<0.001)$ were associated with TB attitude scores (Table 5). In addition, age $(\beta=0.028,95 \% C I 0.007$ to $0.048 ; P=0.007$ ), medical insurance (no: $\beta=-0.494,95 \%$ $C I-0.716$ to $-0.272 ; P<0.001$ ), education level (junior high school or higher: $\beta=0.331,95 \% C I 0.127$ to 0.536 ; $P=0.002$ ), and family annual income per capita (more than 100,000: $\beta=-0.340,95 \% C I-0.564$ to $-0.117 ; P=$ 0.003 ) were associated with TB practice scores (Table 6).

Table 4 Multiple linear stepwise regression analysis of TB knowledge TB among the elderly population

\begin{tabular}{|c|c|c|c|c|c|c|}
\hline Variables & $B$ & $S E$ & Beta & $t$ & $P$ & $95 \% \mathrm{Cl}$ \\
\hline \multicolumn{7}{|c|}{ Education level (ref. primary school or lower) } \\
\hline Junior high school or higher & 0.278 & 0.086 & 0.109 & 3.210 & 0.001 & 0.108 to 0.447 \\
\hline \multicolumn{7}{|c|}{ Family annual income per capita (RMB) (ref. less than 100,000) } \\
\hline More than 100,000 & -0.377 & 0.095 & -0.135 & -3.973 & $<0.001$ & -0.563 to -0.191 \\
\hline Self-perceived health status & -0.245 & 0.072 & -0.115 & -3.379 & 0.001 & -0.387 to -0.103 \\
\hline \multicolumn{7}{|c|}{ Family members or friends with a previous TB history (ref. no) } \\
\hline Yes & 0.624 & 0.238 & 0.088 & 2622 & 0.009 & 0.157 to 1.091 \\
\hline Intercept & 3.413 & 0.225 & & 15.147 & $<0.001$ & 2.971 to 3.855 \\
\hline
\end{tabular}

Abbreviations: $\mathrm{TB}=$ tuberculosis, $\mathrm{SE}=$ standard error

* The self-perceived health status variable was rated as follows: good $=1$, fair $=2$, bad $=3$ 
Table 5 Multiple linear stepwise regression analysis of TB attitudes among the elderly population

\begin{tabular}{|c|c|c|c|c|c|c|}
\hline Variables & $B$ & $S E$ & Beta & $t$ & $P$ & $95 \% \mathrm{Cl}$ \\
\hline \multicolumn{7}{|l|}{ Medical insurance (ref. yes) } \\
\hline No & -0.409 & 0.089 & -0.160 & -4.619 & $<0.001$ & -0.584 to -0.235 \\
\hline \multicolumn{7}{|c|}{ Education level (ref. primary school or lower) } \\
\hline Junior high school or higher & 0.208 & 0.079 & 0.089 & 2.615 & 0.009 & 0.052 to 0.364 \\
\hline \multicolumn{7}{|c|}{ Family annual income per capita (RMB) (ref. less than 100,000) } \\
\hline More than 100,000 & -0.224 & 0.087 & -0.088 & -2.571 & 0.010 & -0.394 to -0.053 \\
\hline \multicolumn{7}{|c|}{ Family members or friends with a previous TB history (ref. no) } \\
\hline Yes & 0.753 & 0.214 & 0.118 & 3.514 & $<0.001$ & 0.332 to 1.174 \\
\hline Intercept & 3.016 & 0.193 & & 15.646 & $<0.001$ & 2.638 to 3.395 \\
\hline
\end{tabular}

Abbreviations: $\mathrm{TB}=$ tuberculosis, $\mathrm{SE}=$ standard error

* The self-perceived health status variable was rated as follows: good $=1$, fair $=2$, bad $=3$

\section{Discussion}

Previous studies have shown that TB KAP were directly associated with the detection rate and TB treatment and prevention effects [14]. The results showed that the core knowledge awareness rate for TB prevention and treatment among elderly people in Shenzhen City was $69.23 \%$, which is higher than the rates reported for residents of Zhejiang Province (48.0\%) [15], Guizhou Province residents (41.5\%) [16], and hospitalized elderly TB patients in Hunan (56.2\%) [17]. However, this rate is considerably lower than the nationwide public TB knowledge awareness rate reported in 2009 (89.0\%) [18]. In terms of each key piece of information about TB, the elderly people had the highest level of correct knowledge about TB's symptoms, which was much better than participants in Lesotho [20]. But what is noteworthy is that a small proportion of respondents knew the transmission routes and curability of $\mathrm{TB}$, which should be strengthened in health education. The percentages of elderly people with positive attitudes and practices regarding TB were 48.87 and $42.62 \%$, respectively, which are slightly higher than the positive attitude rate (40.8\%) and lower than the positive practice rate $(45.9 \%)$ found in residents of Ethiopia [19] and considerably lower than the incidence of positive attitudes reported by Luba et al. [20] for residents of Lesotho (72.8\%). Therefore, implementing further TB health promotion and education efforts among elderly people in the community is an urgent task for the government and related sectors to improve TB prevention and treatment for elderly people.

The results of the multiple linear stepwise analyses showed that the TB knowledge scores of elderly people with higher education levels, lower family annual incomes per capita, a better self-perceived health status, and family members or friends with a previous TB history were higher. Elderly people with a junior high school education or above had higher TB knowledge scores, which is consistent with the findings of Chen et al. [15], Wan [21], and Wang et al. [22]. Elderly individuals with higher annual family incomes per capita had lower TB knowledge scores, which is inconsistent with previous studies [23]. One possible reason is that older individuals have different concerns about health knowledge, and high-income groups may be more knowledgeable in other areas of health knowledge [24]. In addition, because the percentage of people with higher self-reported annual family incomes was relatively low in this study and residents may be sensitive about sharing income information, the number of people with high incomes may have been underestimated.

Table 6 Multiple linear stepwise regression analysis of TB practice among the elderly population

\begin{tabular}{|c|c|c|c|c|c|c|}
\hline Variables & B & $S E$ & Beta & $t$ & $P$ & $95 \% \mathrm{Cl}$ \\
\hline Age (years) & 0.028 & 0.010 & 0.096 & 2.692 & 0.007 & 0.007 to 0.048 \\
\hline \multicolumn{7}{|l|}{ Medical insurance (ref. yes) } \\
\hline No & -0.494 & 0.113 & -1.161 & -4.375 & $<0.001$ & -0.716 to -0.272 \\
\hline \multicolumn{7}{|c|}{ Education level (ref. primary school or lower) } \\
\hline Junior high school or higher & 0.331 & 0.104 & 0.115 & 3.181 & 0.002 & 0.127 to 0.536 \\
\hline \multicolumn{7}{|c|}{ Family annual income per capita (RMB) (ref. less than 100,000) } \\
\hline More than 100,000 & -0.340 & 0.114 & -0.108 & -2.993 & 0.003 & -0.564 to -0.117 \\
\hline Intercept & 1.800 & 0.799 & & 2.252 & 0.025 & 0.231 to 3.370 \\
\hline
\end{tabular}

Abbreviations: $\mathrm{TB}=$ tuberculosis, $\mathrm{SE}=$ standard error

* The self-perceived health status variable was rated as follows: good $=1$, fair $=2$, bad $=3$ 
Intriguingly, this study showed that elderly individuals with higher education levels were more likely to have higher levels of TB knowledge, but individuals with higher incomes were less likely to have TB knowledge, reflecting an interesting finding that requires further research. Educational interventions should be strengthened for elderly people with low education levels and high incomes. Furthermore, this study showed that people with a better self-perceived health status had higher TB awareness. Elderly people with a better selfperceived health status may direct more attention towards health information and their own health; therefore, they were more likely to acquire more TB information. Elderly people whose relatives or friends previously had TB also had more opportunities to be informed about TB and were strongly influenced by its importance. Therefore, they reported higher awareness rates, which also suggests that some individuals successfully received information from the health care system and spread health knowledge. Therefore, health education activities are needed in medical institutions to further health knowledge among the elderly population.

The TB attitude scores of elderly individuals without health insurance were lower. Elderly people with higher education levels and those whose family members or friends with a previous $\mathrm{TB}$ history had relatively positive attitudes towards $\mathrm{TB}$ treatment and prevention. The impact of education level on TB attitude and practices scores was consistent with the impact of knowledge scores, indicating that health education regarding ТB was the key to establishing appropriate health attitudes and practices. Our finding is consistent with the study by Luba et al. [20] among Lesotho residents. In addition, age was positively associated with $\mathrm{TB}$ practices. A possible interpretation may be that people are more likely to adopt active TB prevention behaviours due to decreased immunity and an increased risk of TB with age [23].

The strength of this study is that it is the first study to investigate TB KAP among elderly people in China. The findings may provide targeted guidance for improving health policies. However, this study had some limitations. First, this study targeted elderly people in Bao'an District of Shenzhen; thus, the results are representative of elderly people only in the Shenzhen area instead of China. A survey of elderly individuals in multiple regions across the country is needed to further verify the results of this study. Second, the study population was selected from individuals who received health examinations at the selected health centres. This population already has access to care and may not be representative of those who do not undergo health examinations, which limited the generalizability of our data to other elder populations. Third, we excluded samples with more than $10 \%$ missing values from the data analysis. Those who had better memories were more likely to complete the questionnaire than others, which may lead to selection bias. Forth, the survey was cross-sectional, which limited interpretation of the temporality and causality of these findings. Final, other potential predictors, such as the accessibility of health services, social support, and a history of chronic disease, were not included in this study. More comprehensive and rigorous studies based on scientific sampling are needed.

\section{Conclusions}

Elderly people in Shenzhen City had low levels of TB knowledge awareness and poor attitudes and practices regarding $\mathrm{TB}$ prevention and treatment. Furthermore, this study showed that elderly people with lower education levels and higher family annual incomes per capita had lower overall TB knowledge awareness rates and poor TB-related attitudes and practices. Therefore, the implementation of systemic health education and health promotion activities for elderly people targeting the transmission and curability of TB is recommended.

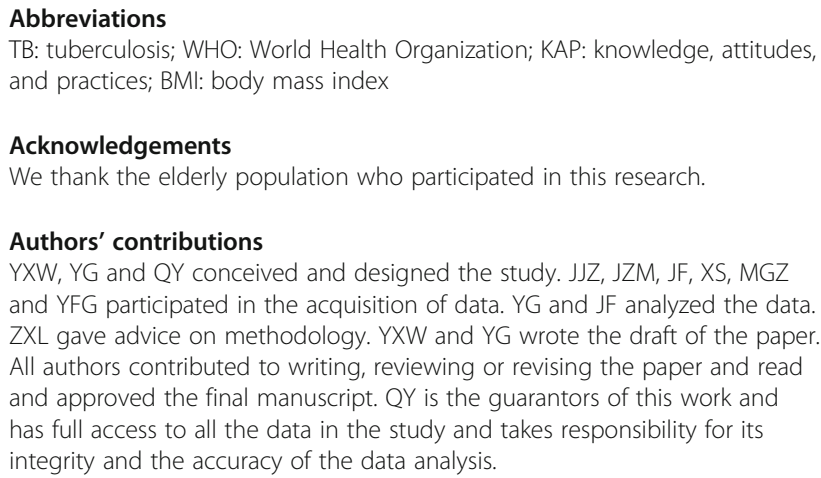

Funding

The study was funded by a Major Infectious Disease Prevention and Control of the National Science and Technique Major Project (2018ZX10715004).

Availability of data and materials

Data may be made available by contacting the corresponding author.

\section{Declarations}

Ethics approval and consent to participate

The study was approved by the Ethics Committee of the Tongji Medical College Institutional Review Board, Huazhong University of Science and Technology, Wuhan, China. Informed consent was obtained from all survey participants. All methods were carried out in accordance with relevant guidelines and regulations.

Consent for publication

Not applicable.

\section{Competing interests}

We declare that we have no conflict of interests.

Author details

${ }^{1}$ Shenzhen Bao'an Center for Chronic Disease Control, NO. 332 Yu'an 2nd Road, Shenzhen 518101, China. ${ }^{2}$ Department of Social Medicine and Health 
Management, School of Public Health, Tongji Medical College, Huazhong University of Science and Technology, Wuhan, Hubei, China.

Received: 20 January 2021 Accepted: 4 June 2021

Published online: 17 June 2021

\section{References}

1. World Health Organization. Global tuberculosis report 2020. Geneva. World Health Organization. 2020. https.//www.who.int/publications/i/item/978924 0013131. Accessed 15 Dec 2020.

2. World Health Organization. China country assessment report on ageing and health. Geneva. World Health Organization. 2016. https.//www.who.int/a geing/publications/china-country-assessment/zh/. Accessed 15 Dec 2020.

3. Cheng J, Sun YN, Zhang CY, Yu YL, Tang LH, Peng H, et al. Incidence and risk factors of tuberculosis among the elderly population in China. a prospective cohort study. Infect Dis Poverty. 2020;9(1):13.

4. Berg-Johnsen A, Hådem SO, Tamrakar D, Harstad I. A questionnaire of knowledge, attitude and practices on tuberculosis among medical interns in Nepal. J Clin Tuberc Other Mycobact Dis. 2020;20(100173):100173.

5. Akande PA. Knowledge and practices regarding tuberculosis infection control among nurses in Ibadan, south-west Nigeria. a cross-sectional study. BMC Health Serv Res. 2020;20(1):280.

6. Dorji T, Tshering T, Wangdi K. Assessment of knowledge, attitude and practice on tuberculosis among teacher trainees of Samtse College of Education, Bhutan. PLoS One. 2020;15(11):e0241923.

7. Alotaibi B, Yassin Y, Mushi A, Maashi F, Thomas A, Mohamed G, et al. Tuberculosis knowledge, attitude and practice among healthcare workers during the 2016 Hajj. PLoS One. 2019;14(1):e0210913.

8. Wang J, LV Q, Chen MT, Xia YY, Cheng J, Zhao F, et al. The national awareness survey on key TB messages in 2015. Chin J Antituberc. 2017; 39(3):282-8

9. Charan J, Biswas T. How to calculate sample size for different study designs in medical research? Indian J Psychol Med. 2013;35(2):121-6.

10. Zhao MG, Wang WX, Tang $Y$, Wang YX, Zhao AG. Survey on knowledge, attitude and practice about tuberculosis prevention and treatment among residents in Bao'an District of Shenzhen. J Clin Pulm Med. 2015:20(9):1567-71.

11. National Health and Family Planning Commission of the People's Republic of China. Notice of the National Health and Family Planning Commission of the People's Republic of China on the issuance of the work plan for the dissemination of knowledge on tuberculosis prevention and control by millions of volunteers and the core information and knowledge points on tuberculosis prevention and control. http://www.nhc.gov.cn/jkj/s3589/201 604/2dd6a74584d34a6ba0dd863544e83416.shtml. Accessed 10 Apr 2021.

12. Ma J. Study on the elderly pulmonary tuberculosis epidemic characteristic in Dongchuan district and awareness of tuberculosis prevention and contro knowledge. Kunming: Kunming Medical University; 2015.

13. Lu CR, Che XL, Li MZ, Wu QF, Zhuo ZP, Yang BL, et al. Investigation on public awareness in key information of tuberculosis prevention and control in Shenzhen. J Tuberc Lung Health. 2019:8(4):259-64.

14. Hoa NP, Diwan VK, Co NV, Thorson AE. Knowledge about tuberculosis and its treatment among new pulmonary TB patients in the north and central regions of Vietnam. Int J Tuberc Lung Dis. 2004;8(5):603-8.

15. Chen X, Wang W, Wang X, Chai C, Liu K, Peng Y, et al. Public Awareness of Tuberculosis in Southeast China. A Population-Based Study. Int J Environ Res Public Health. 2019;16(21):4290

16. Chen W, Li Y, Yang H, Ehiri J, Chen Z, Liu Y, et al. Is tuberculosis health education reaching the public in China? A cross-sectional survey in Guizhou Province. BMJ Open. 2016:6(9):e013534.

17. Wu YM, Liu SS, Gong DH, et al. Investigation and analysis on awareness of tuberculosis prevention and control knowledge among elderly close contacts of tuberculosis patients. Chin J Antituberc. 2020;42(7):701-6.

18. Lu SH, Tian BC, Kang XP, Zhang W, Meng XP, Zhang JB, et al. Public awareness of tuberculosis in China. a national survey of 69253 subjects. Int J Tuberc Lung Dis. 2009;13(12):1493-9.

19. Bati J, Legesse M, Medhin G. Community's knowledge, attitudes and practices about tuberculosis in Itang special district, Gambella region, South Western Ethiopia. BMC Public Health. 2013;13:734.

20. Luba TR, Tang S, Liu Q, Gebremedhin SA, Kisasi MD, Feng Z. Knowledge, attitude and associated factors towards tuberculosis in Lesotho. a population based study. BMC Infect Dis. 2019;19(1):96.
21. Wan Y. Effect evaluation on tuberculosis health education intervention among middle school students in Tianjin. Chin J Sch Health. 2014;35(2): $190-2$.

22. Wang Y, Hu ZP. Survey on awareness of the knowledge about TB among middle school students in Shenzhen City. Chin J Health Educ. 2010;26(7): 516-8.

23. Zhang $L$, Zhou CC. Knowledge acquisition and influencing factors of tuberculosis among floating population in and between provinces. Chin J Public Health. 2019;35(2):147-52.

24. Jiang $Y$, Sun $H$, Li M, He XX. Awareness of knowledge on tuberculosis prevention and control and its influencing factors among new college students in Shijingshan District of Beijng. J Tuberc Lung Health. 2017;(3): 260-4.

\section{Publisher's Note}

Springer Nature remains neutral with regard to jurisdictional claims in published maps and institutional affiliations.
Ready to submit your research? Choose BMC and benefit from:

- fast, convenient online submission

- thorough peer review by experienced researchers in your field

- rapid publication on acceptance

- support for research data, including large and complex data types

- gold Open Access which fosters wider collaboration and increased citations

- maximum visibility for your research: over $100 \mathrm{M}$ website views per year

At BMC, research is always in progress.

Learn more biomedcentral.com/submissions 